\title{
Investigation on Genetic Analysis of Safflower (Carthamus tinctorius L.) Genotypes using Rapd Molecular Markers
}

\author{
S. L. Dhare*, P. B. Wadikar, M. R. Magar and S. J. Sonawane \\ Department of Agricultural Botany, College of Agriculture, Latur, Vasantrao Naik \\ Marathwada Krishi Vidyapeeth, Parbhani-431 402 (MS), India
}

*Corresponding author

\section{A B S T R A C T}

\begin{tabular}{|l|}
\hline Ke y w o r d s \\
$\begin{array}{l}\text { Safflower } \\
\text { genotypes, Genetic } \\
\text { diversity, RAPD. }\end{array}$ \\
\hline Article Info \\
\hline $\begin{array}{l}\text { Accepted: } \\
\text { 20 August } 2019 \\
\text { Available Online: } \\
\text { 10 September } 2019\end{array}$ \\
\hline
\end{tabular}

Knowledge of genetic diversity and relationship among breeding material at molecular level has significant impact on safflower improvement. Genetic diversity of eight parental genotypes of safflower (Carthamus tinctorius L.) was investigated at DNA level with Random Amplified Polymorphic DNA (RAPD) procedure. Forty RAPD primers generated 943 alleles, out of which 679 alleles were found polymorphic, resulting 72.00 per cent polymorphism. The similarity coefficient ranged from 0.42 to 0.76 with an average of 0.59 , thus suggesting considerable genetic variation among the safflower genotypes studied. Further, the dendrogram generated by UPGMA cluster analysis based on Jaccard's similarity coefficient grouped eight parental genotypes into two clusters viz., cluster A and cluster B. Maximum number (7 out of 8) cultivars fell in cluster A. Cluster A was further sub divided in sub cluster $A_{1}$ and $A_{2}$. Least similarity of (0.42) demonstrated by GMU2720 and EC-757665 followed by PBN-96 and EC-757665 as well as by NARI-6 and EC757665. Genotypes, GMU-2720 and PBNS-12, GMU-1339 and PBNS-12 were found to be (0.76) per cent similar based on molecular analysis, but could not consider as duplicate. It may be due to narrowness of the genetic base of widely grown safflower and the results may be different if large number of RAPD primers may use in the study. Our result suggests that, RAPD molecular markers can detect high polymorphism and efficient for assuring genetic diversity and relatedness and also aid in selection of diverse outstanding lines to be used in future breeding programs of safflower.

\section{Introduction}

Safflower (Carthamus tinctorius L.) is one of the most remarkable oldest domesticated Rabi oilseed crop belongs to family Asteraceae. The genus Carthamus is very diverse consist of 36 species, out of which Carthamus tinctorius L. $(2 \mathrm{n}=24)$ is the only cultivated species of safflower which is used as seed and oil extraction while the rest are wild species.
(Dajue and Mundel, 1996). The assessment of the genetic diversity in crop species is of interest for the conservation of genetic resources, broadening of the genetic base and practical applications in breeding programs. In order to design an appropriate breeding program, it is important to know how much the phenotypic variation of a trait is heritable (Kearsey and Pooni, 1996), since the efficiency of a selection program is mainly 
dependent on the magnitude of genetic variation (Falconer and Mackay 1996). Genetic diversity plays a key role in the crop improvement and needed among all correlated varieties, and required for crops evolutionary history and genetic resources (Zada et al., 2013). RAPD primers are extensively used for germplasm categorization and genetic diversity evaluation, gene tagging, in genetic purity testing and also for the identification of cultivars (Shinwari et al., 2013) also it has relatively low cost and high speed is an asset of RAPD markers for evaluation of genetic diversity of different crops (Williams et al., 1990). Therefore, the present study was focused on the characterization of genetic diversity among the eight genotypes of safflower using RAPD markers to provide essential information for future marker facilitated breeding.

\section{Materials and Methods}

The materials included in the study consisted of eight parental lines of safflower genotypes. The seeds of these entries were collected from All India Coordinated Research Programme on Safflower, V.N.M.K.V., Parbhani. The pedigree of the chosen parental genotypes is given in (Table 1.)

\section{Isolation of genomic DNA of safflower genotypes}

The total genomic DNA was isolated from all eight safflower genotypes by CTAB method (Saghai-Maroof et al., 1984).

\section{RAPD analysis}

RAPD PCR amplifications were carried in a total volume of $20 \mu \mathrm{l}$ reaction containing $50 \mathrm{ng}$ of genomic DNA, 1XPCR buffer with $\mathrm{MgCl}_{2}$, $0.2 \mathrm{mM}$ of each dNTP, 2.5pmol primer and 1 unit of Taq DNA polymerase (Aristogene, Bengaluru). PCR tubes were placed in thermal cycler (Sensoquest, Germany) for amplification of the genomic DNA as per the standardized protocol:initial denaturation of 7 min at $94^{\circ} \mathrm{C}$, followed by 40 cycles of $1 \mathrm{~min}$ at $94^{\circ} \mathrm{C}, 1 \mathrm{~min}$ at $36^{\circ} \mathrm{C}, 2 \mathrm{~min}$ at $72^{\circ} \mathrm{C}$ with a final extension step at $72^{\circ} \mathrm{C}$ for $10 \mathrm{~min}$ and hold at $4^{\circ} \mathrm{C}$

\section{Data scoring and analysis}

The banding patterns generated by RAPD primers were examined to determine the level of polymorphism and the genetic relatedness among the safflower parental genotypes. The presence of band at an amplicon level was scored as (1) and its absence as (0). The binary data was analyzed using standard procedure in NTSYS-PC (Version 2.1; Exeter Biological Software, Setauket, NY) software package (Rohlf, 1998). The data were subjected to the SIMQUAL option to obtain association coefficients using Jaccard's coefficient of similarity to generate a similarity matrix. Clustering analysis was performed with the unweighted pair-group method using arithmetic averages (UPGMA) in the SAHN (sequential, agglomerative, hierarchical and nested clustering method) module of NTSYSPC.

\section{Results and Discussion}

\section{Marker polymorphism}

The amplification profiles of the eight safflower parental genotypes produced by the 40 arbitrary oligonucleotide primers revealed a total of 943 bands, 679 of them were polymorphic accounting for $72.00 \%$ polymorphism, with an average of 1.80 polymorphic band per primer pair (Table 2 and Fig. 1). The number of fragments per primer ranged from 9 (OPA-10) to 41 (RPI-6, RPI-14) with an average 23.32 bands per primer pair. Among the 40 RAPD primers, 23 primers showed polymorphism to an extent 
100 per cent while 13 primers were monomorphic and primers RPI-11, RPI-20, OPA-8, OPA-12 showed no polymorphism respectively. The primer RPI-9 and OPA-10 exhibited (100\%) polymorphism with a smaller number of DNA fragments while, the primer RPI 6 showed lowest (37.72) per cent polymorphism. Panahi et al., (2013) detected 65.5 per cent polymorphism among 20 genotypes of safflower using 9 RAPD primers whereas; Safavi et al., (2017) also reported 81.08 polymorphism in 20 safflower genotypes using 13 RAPD primers. Thus, these findings support the results obtained in present research programme.

\section{Cluster analysis}

Determining true genetic dissimilarity between individuals using molecular markers is an important and decisive point for clustering which provides visual idea about variability presented in studied genotypes in addition to assuring the continued genetic improvement. Jaccard's pair wise similarity coefficient values (Table 4.) generated using pooled data of 40 RAPD primers for eight safflower genotypes obvious that parents, viz., GMU-2720 and PBNS-12, PBNS-12 and GMU-1339 showed highest similarity (0.76) and could not be distinguished from each other and fell in nearby sub-cluster. On the other hand, least similarity of (0.42) were revealed by GMU-2720 and EC-757665 followed by PBN-96 and EC-757665 as well as by NARI-6 and EC-757665 indicating more divergent. Such a trend of least similarity between genotypes of $C$. Carthamus L. was also reported by Safavi et al., (2010), Soregaon et al., (2007), Amini et al., (2007). This authors also reported maximum similarities between genotypes of close relationship between their characters while minimum similarities between genotypes possessing different morphological characters. Further, all the eight parental genotypes showed diversity among themselves indicating that there is a considerable amount of variation which can be exploited through appropriate breeding programme.

\begin{tabular}{|c|c|c|c|}
\hline Sr. No. & Parents & Sources & Pedigree \\
\hline 1 & GMU-2720 & AICRP, Parbhani & High yield, low hull content. \\
\hline 2 & PBNS-12 & AICRP, Parbhani & Resistant to wilt and tolerant to aphid. \\
\hline 3 & JMU-1339 & AICRP, Parbhani & High yield, low hull content. \\
\hline 4 & GMU-3423 & AICRP, Parbhani & High yield, Bold capitulum \\
\hline 5 & PBN-96 & AICRP, Parbhani & High yield, low hull content. \\
\hline 6 & NARI-6 & AICRP, Parbhani & Non-spiny, suitable for petal collection. \\
\hline 7 & GMU-3431 & AICRP, Parbhani & Non-spiny, suitable for petal collection. \\
\hline 8 & EC-757665 & AICRP, Parbhani & $\begin{array}{l}\text { Spiny, Resistant to wilt and tolerant to } \\
\text { aphid. }\end{array}$ \\
\hline
\end{tabular}




\begin{tabular}{|c|c|c|c|c|}
\hline Sr. No. & Name of primers & $\begin{array}{c}\text { Total number of } \\
\text { bands }\end{array}$ & $\begin{array}{c}\text { Number of polymorphic } \\
\text { bands }\end{array}$ & $\begin{array}{c}\text { Per cent } \\
\text { polymorphism }\end{array}$ \\
\hline 1 & RPI 1 & 18 & 18 & 100.00 \\
\hline 2 & RPI 2 & 14 & 14 & 100.00 \\
\hline 3 & RPI 3 & 22 & 22 & 100.00 \\
\hline 4 & RPI 4 & 12 & 12 & 100.00 \\
\hline 5 & RPI 5 & 23 & 15 & 65.21 \\
\hline 6 & RPI 6 & 41 & 33 & 37.72 \\
\hline 7 & RPI 7 & 36 & 28 & 77.77 \\
\hline 8 & RPI 8 & 18 & 18 & 100.00 \\
\hline 9 & RPI 9 & 10 & 10 & 100.00 \\
\hline 10 & RPI 10 & 22 & 22 & 100.00 \\
\hline 11 & RPI 11 & 24 & 0 & 0.00 \\
\hline 12 & RPI 12 & 18 & 18 & 100.00 \\
\hline 13 & RPI 13 & 36 & 36 & 100.00 \\
\hline 14 & RPI 14 & 41 & 33 & 80.48 \\
\hline 15 & RPI 15 & 16 & 16 & 100.00 \\
\hline 16 & RPI 16 & 27 & 11 & 40.74 \\
\hline 17 & RPI 17 & 23 & 23 & 100.00 \\
\hline 18 & RPI 18 & 26 & 18 & 69.23 \\
\hline 19 & RPI 19 & 25 & 25 & 100.00 \\
\hline 20 & RPI 20 & 24 & 0 & 0.00 \\
\hline 21 & RPI 21 & 18 & 10 & 55.55 \\
\hline 22 & RPI 22 & 17 & 17 & 100.00 \\
\hline 23 & RPI 23 & 16 & 16 & 100.00 \\
\hline 24 & RPI 24 & 18 & 18 & 100.00 \\
\hline 25 & RPI 25 & 19 & 19 & 100.00 \\
\hline 26 & OPA 1 & 33 & 1 & 96.96 \\
\hline 27 & OPA 2 & 38 & 30 & 78.94 \\
\hline 28 & OPA 3 & 13 & 13 & 100.00 \\
\hline 29 & OPA 4 & 32 & 32 & 100.00 \\
\hline 30 & OPA 5 & 25 & 25 & 100.00 \\
\hline 31 & OPA 6 & 18 & 10 & 55.55 \\
\hline 32 & OPA 7 & 26 & 26 & 100.00 \\
\hline 33 & OPA 8 & 32 & 0 & 0.00 \\
\hline 34 & OPA 9 & 39 & 7 & 82.05 \\
\hline 35 & OPA 10 & 9 & 9 & 100.00 \\
\hline 36 & OPA 11 & 18 & 10 & 55.55 \\
\hline 37 & OPA 12 & 24 & 0 & 0.00 \\
\hline 38 & OPA 13 & 29 & 29 & 100.00 \\
\hline 39 & OPA 14 & 27 & 19 & 70.37 \\
\hline 40 & OPA 15 & 16 & 16 & 100.00 \\
\hline \multicolumn{2}{|r|}{ Total } & 943 & 679 & 72.00 \\
\hline
\end{tabular}




\begin{tabular}{|l|l|}
\hline \multicolumn{2}{|c|}{ Table 3. Summary statistics of RAPD analysis in parental lines of safflower } \\
\hline Features & RAPD \\
\hline Total number of markers used & 40 \\
\hline Total number of bands & 943 \\
\hline Maximum number of bands generated by marker & 41 \\
\hline Minimum number of bands generated by marker & 9 \\
\hline Total number of polymorphic bands & 679 \\
\hline Per cent polymorphism & 72.00 \\
\hline Average polymorphism & 1.80 \\
\hline Average number of bands per marker & 23.32 \\
\hline
\end{tabular}

\begin{tabular}{|c|c|c|c|c|c|c|c|c|}
\hline Parents & 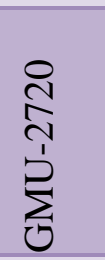 & $\begin{array}{l}\frac{1}{1} \\
\dot{n} \\
\underline{a}\end{array}$ & 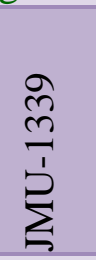 & 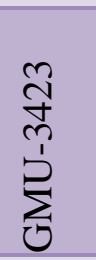 & $\begin{array}{l}0 \\
a \\
z \\
a \\
a\end{array}$ & $\begin{array}{l}0 \\
\frac{1}{\alpha} \\
\frac{\alpha}{z} \\
\end{array}$ & 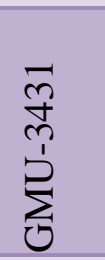 & 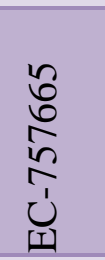 \\
\hline GMU-2720 & 1.00 & & & & & & & \\
\hline PBNS-12 & 0.76 & 1.00 & & & & & & \\
\hline JMU-1339 & 0.52 & 0.76 & 1.00 & & & & & \\
\hline GMU-3423 & 0.58 & 0.70 & 0.74 & 1.00 & & & & \\
\hline PBN-96 & 0.52 & 0.64 & 0.56 & 0.70 & 1.00 & & & \\
\hline NARI-6 & 0.60 & 0.64 & 0.68 & 0.66 & 0.52 & 1.00 & & \\
\hline GMU-3431 & 0.68 & 0.62 & 0.54 & 0.56 & 0.74 & 0.62 & 1.00 & \\
\hline EC-757665 & 0.42 & 0.54 & 0.54 & 0.44 & 0.42 & 0.42 & 0.44 & 1.00 \\
\hline
\end{tabular}


Fig. 1 DNA amplification pattern of parental genotypes using RAPD primers
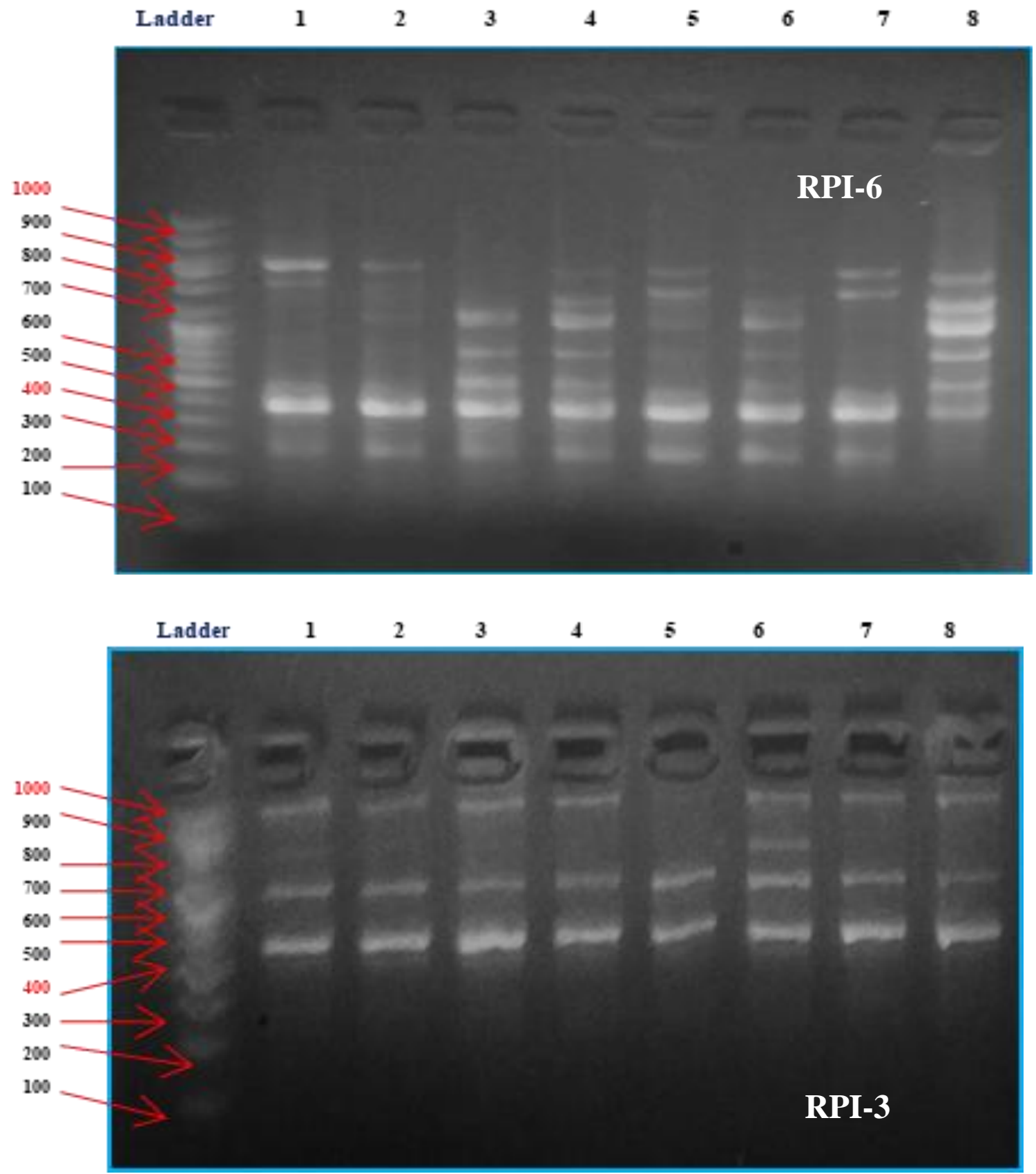

Whereas,

$$
\begin{array}{llll}
\mathbf{1}=\text { GMU }-2720 & \mathbf{5}=\text { PBN-96 } \\
\mathbf{2}=\text { PBNS-12 } & \mathbf{6}=\text { NARI-6 } \\
\mathbf{3}=\text { GMU-1339 } & \mathbf{7}=\text { GMU-3431 } \\
\mathbf{4} & \text { GMU-3423 } & \mathbf{8}=\text { EC-757665 }
\end{array}
$$


Fig. 2. Dendrogram derived from UPGMA cluster analysis using Jaccard's coefficient lines of safflower. based on RAPD markers in parental

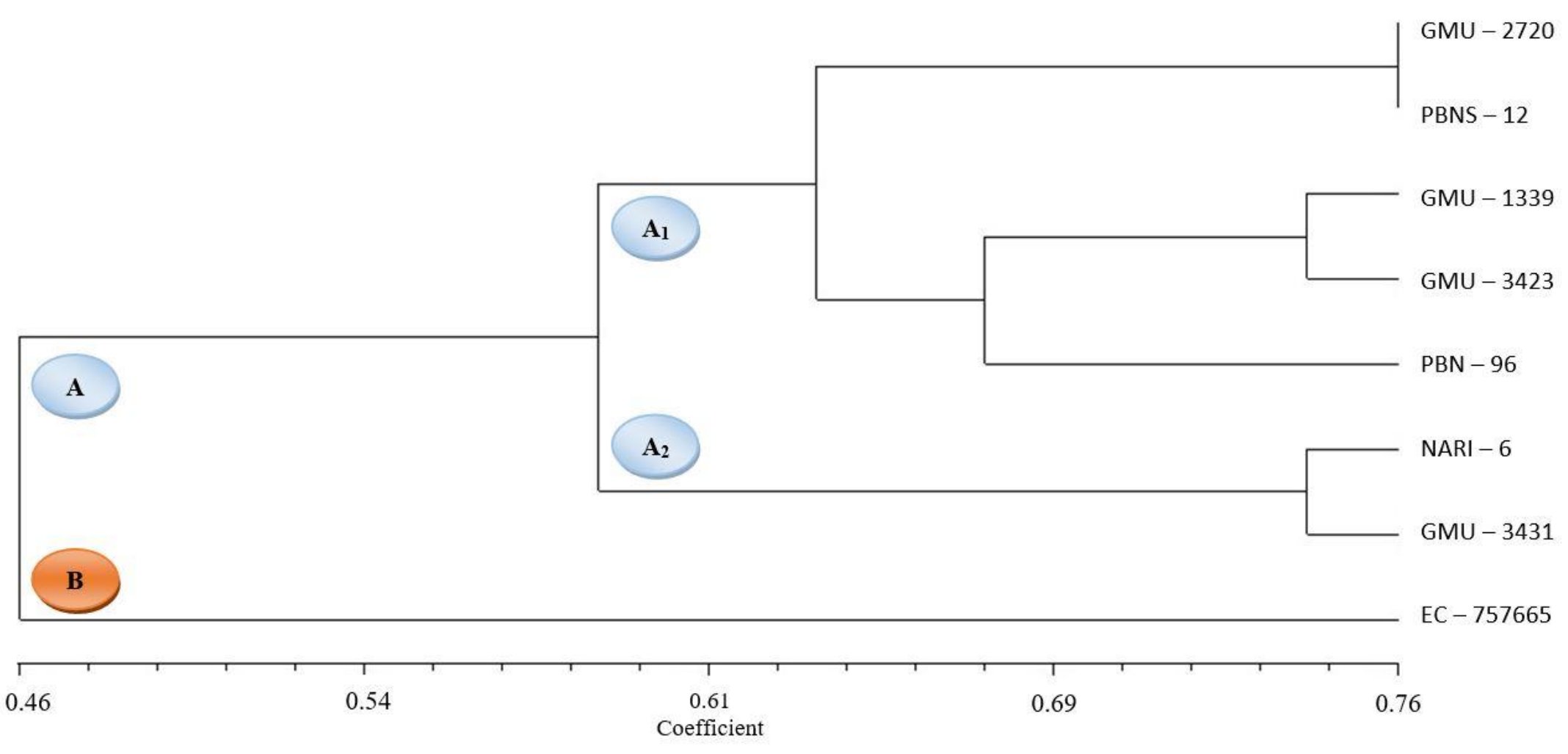


Dendrogram generated by UPGMA clustering pattern of eight genotypes using RAPD markers (Fig. 2) ranges the similarity coefficient from 0.46 to 0.76 . The dendrogram clearly revealed two clusters named as cluster A and cluster B having similarity coefficient 0.46. Maximum number (7 out of 8 ) of cultivars fell in cluster A. Cluster A was subdivided into two sub-clusters, $\mathrm{A}_{1}$ and $\mathrm{A}_{2}$ having similarity coefficient 0.59 . Sub-cluster A1 has Five genotypes viz., GMU-2720, PBNS-12, GMU-1339 and GMU-3423, PBN96 with higher similarity. Out of these, GMU2720, PBNS-12 and GMUU-1339, PBNS-12 showed high genetic similarity (0.76) and could not be distinguished from each other and fell in nearby sub-cluster. Sub-cluster A2 have two genotypes viz., NARI-6 and GMU3431 which were found to genetical similarity (0.74). Genotype, EC 757665 remained isolated forming an out group from the rest of genotypes in cluster B. Earlier, Soregaon et al., (2007), Panahi et al., (2013) and Wadikar et al., (2017) also reported this type of similar clustering. In the present study, however genotypes GMU-2720 and PBNS-12 and GMUU-1339 and PBNS-12 were found to be 0.76 per cent similar based on molecular analysis, but could not be considered as duplicates. It may be due to narrowness of the genetic base of widely grown safflower genotypes and the results may be different if large number of RAPD primers may use in the study.

The present study suggest that, with the help of clustering pattern and genetic relationship, breeder can identify the diverse genotype with least similarity from clusters and employ them in the future breeding programmes of safflower.

The molecular characterization of these genotypes based on RAPD is faster, less expensive and more reliable.

\section{References}

Amini, S. F., Arzani G. and Ahmad, A. (2008). Study of genetic diversity in safflower genotypes using agromorphological traits and RAPD markers. Euphytica., 163(1): 21-30.

Dajue, L., Mundel, H. H. (1996). Safflower. Carthamus tinctorius L. Promoting the conservation and use of underutilized and neglected crops. Institute of Plant Genetics and Crop Research, Rome.

Falconer, D. S, Mackay, TFC (1996). Introduction to quantitative genetics. Longman, Harlow, UK.

Kearsey, M. J. and Pooni, H. S. (1996). The genetical analysis of quantitative traits. Chapman and Hall, London.

Panahi, B., Afzal, R., Ghorbanzadeh, N. M., Mahmoodnia, M. and Paymard, B. (2013). Relationship among AFLP, RAPD marker diversity and Agromorphological traits in safflower (Carthamus tinctorius L.). Progress in Biological sci., 3(1): 99-90.

Rohlf, F. J. (1998). NTSYS-pc: Numerical taxonomy and multi variety analysis system. Exeter Publishing, Setauket. $119 \mathrm{Pp}$.

Safavi, S. M., Pourdad, S. S. and Safavi, S. A. (2017). Analysis of genetic diversity of safflower. (Carthamus tinctorius L.) genotypes using Agro-morphological traits and Molecular markers. Philippine J. crop sci., 42(2): 48-48.

Saghai-Maroof, M.A., Soliman, K.M., Jorgensen, R.A. and Allard, R.W. (1984). Ribosomal DNA spacer length polymorphism in barley; Mendelian Inheritance, chromosomal location and population dynamics. Proc. Natl Acad. Sci. USA, 81, 8014-8018.

Shinwari, Z. K. (2013). Genetic divergence in Taramira (Eruca sativa L.) germplasm based on quantitative and qualitative characters. Pak. J. Bot., 45: 375-381. 
Soregaon, C. D., Ravikumar, R. L. and. Satish, D. (2007). Molecular diversity in Carthamus species and species identification using RAPD markers. Ind. J. Genet. Pl. Breed., 67(4): 347351.

Wadikar, P. B., Solanki B. G., Patel, D. H. and Narwade, A. V. (2017). RAPD based assessment of genetic diversity in upland cotton (Gossypium hirsutum L.). Multilogic in sci., 6(19): 230-233.
Williams, J. G. K., Kubelik, A. R., Livak, K. J., Rafalski, J. A. and Tingey, V. (1990). DNA polymorphisms amplified by arbitrary primers are useful as genetic markers. Nucleic Acid Res., 18:6531-6535.

Zada, M., Shinwari, Z. K., Nahida, Z. and Rabbani, M. A. (2013). Study of total seed storage proteins in Ethiopian mustard (Brassica carinata A. Braun) germplasm. Pak. J. Bot., 45: 443-448.

\section{How to cite this article:}

Dhare, S. L., P. B. Wadikar, M. R. Magar and Sonawane, S. J. 2019. Investigation on Genetic Analysis of Safflower (carthamus tinctorius 1.) Genotypes using Rapd Molecular Markers.. Int.J.Curr.Microbiol.App.Sci. 8(09): 1919-1927. doi: https://doi.org/10.20546/ijcmas.2019.809.222 